\title{
The Hybrid Color Film: Multiplicity of Space, Time, and Matter
}

Hybrid color films of the 1920s such as The King of Kings (Cecil B. DeMille, 1927)that is, films comprising a mix of different historical color processes-are a particularly fruitful resource for the comparison of the silent era's various color technologies. This article analyzes these cinematic hybridizations and argues that this type of film is much more than the sum of its parts. In embodying a multiplicity of layers of space, time, and color on a literal and metaphorical level, hybrid color films are not only symptomatic of the transformation of the medium in the 1920s but also symbolic of current approaches to film historiography based on media archaeology.

\section{Keywords}

HYBRIDITY

HYBRID FILM

COLOR FILM PROCESSES

TECHNOLOGY

MATERIALITY

$1920 S$

TEMPORALITY

FILM HISTORIOGRAPHY

DIGITAL RECONSTRUCTION

DIGITAL RECREATION

Date submitted: $29 / 4 / 2021$

Date accepted: $24 / 9 / 2021$

Olivia Kristina Stutz

oliviakristina.stutz@uzh.ch orcid.org/0000-0001-6574-480X

Olivia Kristina Stutz is a PhD student within the ERC Advanced Grant FilmColors project at the Department of Film Studies of the University of Zurich under the supervision of Professor Barbara Flueckiger. Her research focuses on the relation between the technology and aesthetics of analog color film processes from the 1890s to the mid-1930s with special interest in film materiality and the application of digital humanities tools. 


\section{Introduction}

The twentieth century witnessed the invention and deployment of hundreds of diverse analog color film processes, each with its own material aesthetic and characteristic color style associated with the technology. The hybrid color films (that is, films that use multiple coloring techniques) of the 1920s are thus not only a valuable resource for comparing the different color technologies of the era of silent film, but also furnish an illustration of how the parameters of filmic space, time, and color interact on a literal and a metaphorical level. The field of film studies has dealt with the subject of color hybridity in differing ways.

Among the most significant theoretical contributions are Philippe Dubois's "Hybridations et métissages" (1995), which focuses on the dialectics of chromatic hybridization in early film and classical Hollywood cinema;

Richard Misek's (2010) overview of color cinema and (inter alia) hybrid film up to the early 2000 s in relation to the changing approaches to the function of color and black and white; and Sarah Street and Joshua Yumibe's Chromatic Modernity (2019), which includes an analysis of hybrid color films of the 1920s from an intermedial perspective. Although I, too, discuss the relationship between technology and aesthetics in this article, as well as aspects of intermediality, my primary concern is to theorize the phenomenon of cinematic hybridizations using color film of the 1920 s as a case study.

The concept of artistic hybridity is widespread in the field of visual arts, especially in mixed media art. The birth of mixed media itself is typically associated with cubism. In the early twentieth century, artists such as Pablo Picasso and Georges Braque began to integrate "ahistorical" and/or "unartistic" materials (e.g., fabric, paper, found objects) into their artworks, creating assemblages and collages aimed at undermining the classicist-academicist dogma of mimesis in figurative art using "traditional" materials (Wagner [2001] 2013, 33). Mixed media artworks, then, embody two or more (traditionally unique) media and/or materials, and in this sense, are marked by a particular medial/material hybridity. Jerrold Levinson $(1984,6)$ argues that an art form's status as hybrid-that is, its constitution as hybrid or as a type of hybridity-can only be recognized in relation to the historical context of its creation and its acknowledgement as a medium or as an artistic material or technique. Levinson, however, only discusses the moving image very briefly: he regards silent film as a hybrid of photography and theater $(1984,7)$; sound film as a hybrid of sound and film $(1984,5)$; and abstract color film as a remediation of painting and black-and-white film $(1984,11)$. Although I would argue that this is an oversimplification of the derivation of the medium, I will return later in the article to his underlying idea that the relationship between hybridizations and technical and material developments (here, the cinematic techniques of sound and color) may seed new (film) art and (film) styles, and, in certain historical contexts, media transformations. If we apply this concept of hybridity in early twentiethcentury art to the hybrid color films of the 1920s-which combine different media, not in the primary sense of art forms, but in terms of their manifold film materials and (among other things, intermedial) coloring technologiesthe numerous color film processes they deploy become analogous to the range of painting materials and techniques used in crafts and the fine arts (e.g., watercolors, oils, etc.), rendering these films as mixed media art or some type of hybrid art form.

Although determined by this very material hybridity, hybrid color 
films are nevertheless much more than the sum of their material parts; each color film technology carries its own history and artistic agenda or agency. Drawing methodological inspiration from media archeology's historiographical approaches to temporality and cinema (Strauven 2013, 68-73), this article considers color processes as both literal and symbolic layers of filmic space and time shaping the hybrid color film's material history and aesthetics. I argue that a hybrid color film is marked by its multiplicity of space, time, and matter, and by a particular simultaneity of the non-simultaneous: an expression applied in recent years in predominantly Marxist theories of modernity and postmodernity (e.g., Jameson 1991) and in the field of historiographic research (e.g., Koselleck 2000). These characteristics present a vivid challenge to the linear model of classical color film historiography. Overall, the hybrid color film's heterogeneous structure creates a chromatic dialectics that could be described by the term ästhetische Eigenzeiten, which refers to a complex modeling of and reflection on (film) matter and (filmic) temporality (Gamper and Hühn 2014, 24). This is especially true for the hybrid color films of the 1920s, which are symptomatic of the technical and stylistic transformations of the cinematic medium at the time.

Before diving deeper into this argument, however, we need to take a comparative overview of historical color film processes in order to better conceptualize color film hybridity.

\section{Historical color film processes until the end of the 1920s}

As Dubois (1995, 75-79)

demonstrates, hybrid color films have existed since the very beginning of cinema. In the period of early cinema, black and white was often combined with various applied color film processes, including the early autonomous film coloring techniques of tinting, toning, and hand and stencil coloring. Tinting was a direct and relatively cheap dyeing technique in which a black-and-white positive was submerged into a dye bath that uniformly stained the films' gelatin but left the black silver image intact (Read 2009, 13). Toning, meanwhile, comprised a complex chemical reaction in which the metallic silver was eventually replaced by a colored compound, either a pigment or a dye (2009, 14-15). This technique added color to the developed silver parts of the film image while the silverfree areas (the whites) remained transparent. Hand and stencil coloring, on the other hand, relied on the application of dyes to the surface of a black-and-white film emulsion. Hand coloring involved delicate work, frame by frame, using very fine brushes and magnifying glasses (Yumibe 2012, 4148), while semi-automatic stenciling required pantographs, several separate stencils for each color, and brush rollers (2012, 85-90). Both systems were extremely time-consuming and costly, even though stenciling eventually became more or less mechanized. Aesthetically, they were generally marked by the use of selective colors on black-and-white film, although both processes could also be used to comprehensively color the film image. A typical hybrid film of the time is the fantasy film Excursion to the Moon (Excursion dans la lune, Segundo de Chomón, 1908), which comprises tinted, toned, and stencil-colored segments.

As a result of the transition from short to feature-length films during the early 1910s, and the respective changes in film narration, color schemes that were dependent on color processes became more diverse (Mazzanti 2009, 69). By mid-decade, a new (applied) color film technology 
called Handschiegl had expanded the existing technical spectrum of color film. This was based on a reversed manual stencil technique combined with the principles of dye imbibition (Cherchi Usai 1995, 101-03). Although it shared some visual similarities with stenciling, Handschiegl, in principle, was a three-color "graphic arts process" (Read 2009, 16) that was able to overlay three layers of color. An example of a hybrid color film of the 1910 s is the historical drama Joan the Woman (Cecil B. DeMille, 1916), which contains black-and-white, tinted, toned, and Handschiegl elements, depending on the version.

But applied colors were, of course, not the only color technologies available. Mimetic colors, in contrast to applied colors, relied on the automatic registration of color on panchromatic negative film, which was sensitive to all the color wavelengths of the visible light spectrum. For this reason, mimetic color film processes, at least in theory, were assumed to depict the colors of the profilmic setup "mimetically" or "accurately." These socalled "natural colors" were achieved by two different means: additive and subtractive color synthesis (Ryan 1977, 12-15). These technologies had already been invented by around 1900, reaching their first peak with the additive system Kinemacolor at the end of the first decade of the twentieth century (McKernan 2013, 76-86), to be followed by many more in the next decade (Cherchi Usai 2000, 33-37). Yet, mimetic colors were not widely used in the film industry of the time because, unlike applied colors, they were more expensive and geographically restricted by patents.

In fact, the breakthrough of these two-, three-, or even four-color mimetic systems came in the 1920 s, when many of them were invented and/or implemented in the Western film market. Technicolor no. III, for example, was a subtractive twocolor technology from the late 1920s based on a dye-transfer process involving the successive transfer of two complementary colored dye layers (typically orange-red and green-blue) onto a single-coated blank film, with the aid of two relief matrices and direct contact pressure (Layton and Pierce 2015, 142-45). The final (rendered) color image was a consequence of the actual mixing of the chosen primary colors using this colorization technique. I discuss several of these 1920s color films below.

\section{A conceptualization of material hybridity}

Following this technical description of historical color film processes, we now need to seek a more refined conceptual definition of the (material) hybridity of such films. For instance, while a tinted film is strictly speaking a combination of black-and-white film and a dye, it is not usually regarded as a hybrid since the practice of dyeing is an inherent characteristic of the dyeing process itself. If, however, a blackand-white film encompasses tinted intertitles-a common phenomenon in silent cinema-we could, theoretically, speak of a hybrid film, although not necessarily of a hybrid color film (provided that black-and-white is not considered a color). The terminological distinction is necessary since the term hybrid film is also used for the part-talkies, interspersing silent with audible sequences, that emerged during the 1920s (Crafton 1999). Meanwhile, in Germany, the term Mischfilm is more common, but this typically denotes the combination of animation and live action (Forster 2013). To complicate matters further, Dubois calls films with double effects - that is, the simultaneous combination of hand or stencil coloring with black-and-white film"hybridations" $(1995,77)$, whereas he 
uses the term "métissages" $(1995,76)$ for the successive mixing of coloring systems. He thus differentiates between hybrid effects at the level of the individual film image and the hybrid art form of the whole film. For all these reasons, I would suggest that a hybrid color film can only be acknowledged as such if the film contains at least two or more color processes.

The typology proposed by Levinson $(1984,8)$ for the different types of hybrid art forms- "juxtaposition," "synthesis," and "transformation"-is equally useful for the realm of color film as it needs only minor adjustments. For example, juxtaposed color film hybrids would then denote the additional, successive combination of at least two clearly distinguishable color processes "presented as one larger, more complex unit" $(1984,8)$. Synthesizing color film hybrids $(1984,9-10)$ would then refer to the simultaneous fusion of two or more color processes, such as the mixing of tinting with stencil, in such a way that the separate elements synthesize with each other and, to some extent, lose their original characteristics. By contrast, a mimetic color film, which entails, for instance, a form of double toning, cannot be conceived of as a hybrid color film in the primary sense since (as mentioned earlier) the colorization strand is an intrinsic part of the conceptual creative process, similar to the way that traditional oil painting relies on a preparatory underpainting. The third kind of hybrid art form mentioned by Levinson, the transformational hybrid (1984, 10-11), which refers to the metamorphosis of one medium into another, needs the most alteration if it is to apply to the field of color film. Nevertheless, the term could possibly be applied to material, aesthetic, and even epistemological alterations caused by a film's provenance and preservation. Film provenance denotes the journey of a film's material essence across space and time, and its transformation by archival practices that use certain preservation methods, such as the duplication of historical film onto another (modern) film stock, or digital restorations and reconstructions (Fossati 2009, 73-76), illustrating the film's mutability as a "multiple object" (Cherchi Usai 2000, 160). These archival interventions transform the analog color film aesthetics into something similar yet different. In this procedure, the essential features of the color process(es) are "challenged, modified, or withdrawn" (Levinson 1984, 10).

Drawing on this theory of hybridity, the expression hybrid color film in this article refers to the combination of a range of historical coloring techniques or technologies used simultaneously (juxtaposition) and/or successively (synthesis) within a single film. Thus, the recognition of a hybrid color film as a hybrid requires an identification of the color processes and depends, in its aesthetic considerations, on the version of the film, since different prints of the same film can vary greatly for economic or geographic reasons, and/or reasons of provenance. A critical awareness of the film source (that is, whether it is DVD, Blu-ray, etc.) is especially important when it comes to the period of early color film, as it can lead to substantial differences in terms of length, color scheme, restoration, or reconstruction (Lameris 2017, 120-23). For this reason, we must pay special attention to the hybrid color film's material sources, particularly in relation to the category of the transformational hybrid.

\section{The context of film production in the 1920s \\ Now that we have a terminological toolbox for the (material) conceptualization of hybrid color films, it is time to establish the context of film production in the 1920 s, and its}


significance for the aesthetics of its thriving hybrid art forms.

As a consequence of the many experimentations with film color, the aesthetic development of the hybrid color film reached its first peak during the 1920s (Street and Yumibe 2019, 205). This is the period in which a variety of epistemologically different color processes were systematically juxtaposed or fused, generating the feature-length format that is the focus of this article. The increased experiments with hybridity and film color can be explained by the Hollywood film industry's contemporary technological, aesthetic, and cultural production context. Alongside the emergence of new color film processes, panchromatic film stock, although invented before, was implemented across the board in the mid-to-late 1920s (Thompson 1985, 281-85), and film color palettes were significantly extended with the introduction of new, subtle pastel shades. Just as color became a modern paradigm in the visual arts, so it also infiltrated every aspect of everyday life through the influx of colorful consumer goods, reaching a peak in the $1920 \mathrm{~s}$ (Blaszczyk 2012). The culture of the 1920s, as Street and Yumibe (2019, 205) argue, was marked by a "chromatic hybridity"- "a mixing of color styles and techniques" - that had a strong impact on the intermedial aesthetics of hybrid color films.

However, in the late 1920s and the early 1930s, color film was subject to an existential "crisis" and a period of techno-aesthetic "transition." A number of key problems influenced the visual heterogeneity of these films: the gradual (but far from complete) transition from applied to mimetic colors and their lack of compatibility with prior film technologies; mimetic color's excessive costs and partially unconvincing aesthetic results; the general uncertainty of color cinema in contrast to its blackand-white rival; the race between the various photographic systems for their widespread adoption and eventual standardization within the film industry; and the continuing conversion to sound film (Bordwell 1985b, 298-304), which forced color film technologies to adjust. In fact, the high cost of color-whether stencil, Handschiegl, or mimetic colorprolonged the existence of the hybrid color film (Street and Yumibe 2019, 223) and was another pragmatic reason why the elaborate color schemes of the 1920s occurred in the first place. At the same time, ideological and moral debates about supposedly vulgar mimetic color films versus the artistry of black-and-white film in film-practice and media discourses, and general psychological reservations about photographic color (Coates 2010, 45-54), probably impacted the production of color films further. These combined developments made the 1920s an era of technological and aesthetic experimentation in the color motion-picture industry in general and an important period of change for the film medium in particular. The hybrid color films produced in the 1920s can be understood as a symptom of these techno-aesthetic transformations and negotiations: they were both an unconscious expression of this transitional crisis in the film industry and a conscious product of the impulse for visual storytelling in a diverse chromatic culture.

\section{Form and style in 1920s hybrid color films}

The form and style of the hybrid color films of the 1920s depended not only on the type and amount of color processes but also on their genre and geographical origin. French hybrid color films, for instance, typically included a great variety of fusions of tinting and toning, juxtaposed with black and 
white and sometimes stencil color, as seen in some versions of The Wheel ( $L a$ Roue, Abel Gance, 1923). From 1905 up to the 1920s, the French company Pathe was one of the most established institutions in the world, renowned for the artistry of its stenciling (O'Brien 2012, 300-06), which to some degree explains the presence of the coloring process in the French film. On the other hand, American hybrid color films, until about the mid-1920s, tended to employ a mixture of tinting and/ or toning alongside black and white, and occasionally Handschiegl, as seen in The Affairs of Anatol (Cecil B. DeMille, 1921), Salomé (Charles Bryant, 1922), and Greed (Erich von Stroheim, 1924). Films from later in the decade, however, often embodied a subtractive color process alongside or instead of Handschiegl; for example, Venus of the South Seas (James R. Sullivan, 1924) with Prizma II, Ben-Hur. A Tale of Christ (Fred Niblo, 1926) with Technicolor no. II, and Hell's Angels (Howard Hughes, 1930) with Handschiegl and Multicolor or Technicolor no. III. The combination of applied and subtractive color was practical because, in contrast to most additive systems, there was no need for additional adjustments during projection. Moreover, this arrangement can also be explained by the fact that Handschiegl, Prizma II, Multicolor, and Technicolor all originated in the US itself. One such American hybrid color film from the late 1920s is the biblical epic, The King of Kings (Cecil B. DeMille, 1927).

\section{Case study: The King of Kings}

This hybrid color film narrates the story of the Miracles and Passion of Christ, taking the spectator through a journey in time to a distant past in Palestine around AD 30, when the Jews were under the subjugation of Rome. After performing several miracles -including the casting out of seven deadly sins from
Mary Magdalene, portrayed as an extravagant courtesan-Jesus and his apostles enter Jerusalem, where he is proclaimed King of the Jews by the people. But Jesus renounces all claims to the earthly throne. He is later betrayed by Judas in the Garden of Gethsemane, and soon after captured by Roman soldiers and sentenced to death by crucifixion. After his death, he is taken down from the cross and buried, only to rise from the dead three days later and proclaim his religiously motivated message to the world.

According to the film-restoration booklet from the 2017 reconstruction by Lobster Films (2017, 17-20), there were three versions circulating in the 1920s: a 1927 silent, long, prestige premiere version, embellished by a variety of color processes; a 1928 censored version; and a well-known short version from the same year, with a photophone music score and sound effects. The following analysis refers to the reconstructed premiere version of The King of Kings, which I will use to illustrate my argument that hybrid color films contain a multiplicity of space, time, and matter, and that their form and style demonstrate the concept of the simultaneity of the nonsimultaneous. To this end, I will address questions of film matter-or film material-in relation to (filmic color) space, and (historiographical) time successively.

\section{Matter}

In terms of film matter, the reconstructed premiere version contains four color processes in total (or "simultaneously"), besides the black-and-white intermission title. These are the applied coloring technologies of tinting, toning, in synthesis with hand coloring, and the juxtaposed subtractive two-color system, Technicolor no. III. In fact, this was the first time the mimetic process 
had been used on a large scale for a feature color film (Layton and Pierce 2015, 183-84). Since this article relies on the assumption that each color film process has its own material aesthetic, the type and placement of these color elements in a hybrid color film play a decisive role in its aesthetics. Mixing several color film elements creates peculiar aesthetic effects that are reminiscent of modern mixed media art. By deliberately forming the previously individual color elements into a new and more complex unity, The King of Kings not only enchants the viewer with a relatively flamboyant color scheme, but is alsoas Levinson $(1984,11)$, referring to hybrid art forms, remarks - a symbol "of creativity itself." This makes all the more sense if we recall the transitional film production context of the 1920s with its dynamic experiments with film color. A similar phenomenon of artisanal material mixture, which is more readily associated with creativity but with a different effect, meaning, and/or context, can be traced in the experimental cinema of the first and second wave of avantgarde filmmaking, which operated with diverse materials and cinematic techniques. It can also be seen in the archival film mashups of foundfootage films, which use montage to organize film matter anew in space and time, and in the various hybrid films of another period of "momentous media change" (Elsaesser 2012, 587): the transition from analog to digital technology in the 2000s, which mixed epistemologically different materials or technologies (e.g., video, film) to create new, expressive film styles (Flückiger $2012,87)$. Whereas this certainly also leads us to the question of whether a wider relationship between mixed media art forms and certain periods of transition or transformation can be established, the particular material combination in The King of Kings, and, as we are about to see, the interactions of these materials, are surely one of the main characteristics and attractions of the film type.

\section{Space}

As in many other hybrid films of the time, the choice and placement of a color process is often motivated by narrative and the respective construction of cinematic spaces over the film's viewing time. For instance, expensive and/or new color processes are reserved almost exclusively for a few visually spectacular sequences (Street and Yumibe 2019, 205-06). This principle is also applied in The King of Kings, and in such a way that the "spectacular" Technicolor no. III is used for the introduction of Mary Magdalene (Jacqueline Logan) as a femme fatale in the scene of the opulent feast at the beginning of the film, as well as for the Resurrection sequence at the film's climax, which takes place in an idyllic spring environment (Fig. 1).

A similar strategic placement concerns the double effect of a blue tone fused with delicate orange hand coloring in the Kiss of Judas sequence played out in the Garden of Gethsemane. This occurs in the middle of the film (Fig. 2), immediately after the intermission, and marks the beginning of the film's second part. The sequence is also an example of how a coloring technique can be motivated by a film's visual motifs - here, by the diegetic, glowing torches (hand coloring) and the moonlight effects (blue toning).

The cheapest color process of all, tinting, is used as the film's standard means of coloration and, as such, portrays many different cinematic spaces over the course of the film. Consequently, the hybrid color film is not only an expression of its technological-historical era and geographical origins, but its aesthetics also reflect the semantic hierarchy and 
Fig. 1: Technicolor no. III at the beginning (top) and towards the end (bottom) of The King of Kings (Cecil B. DeMille, 1927) (c) 2017 Lobster Films
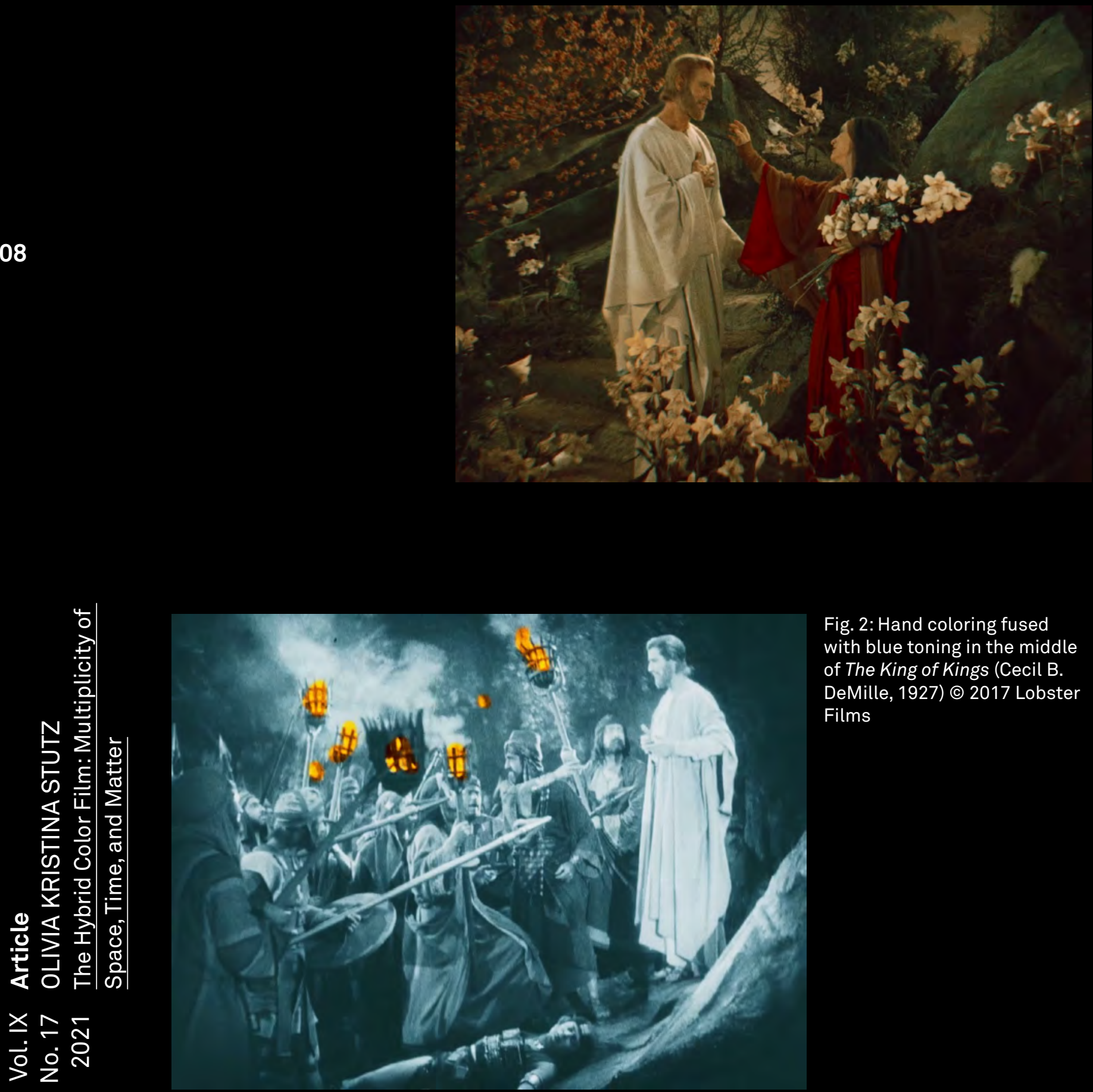

Fig. 2: Hand coloring fused with blue toning in the middle of The King of Kings (Cecil B. DeMille, 1927) @ 2017 Lobster Films 

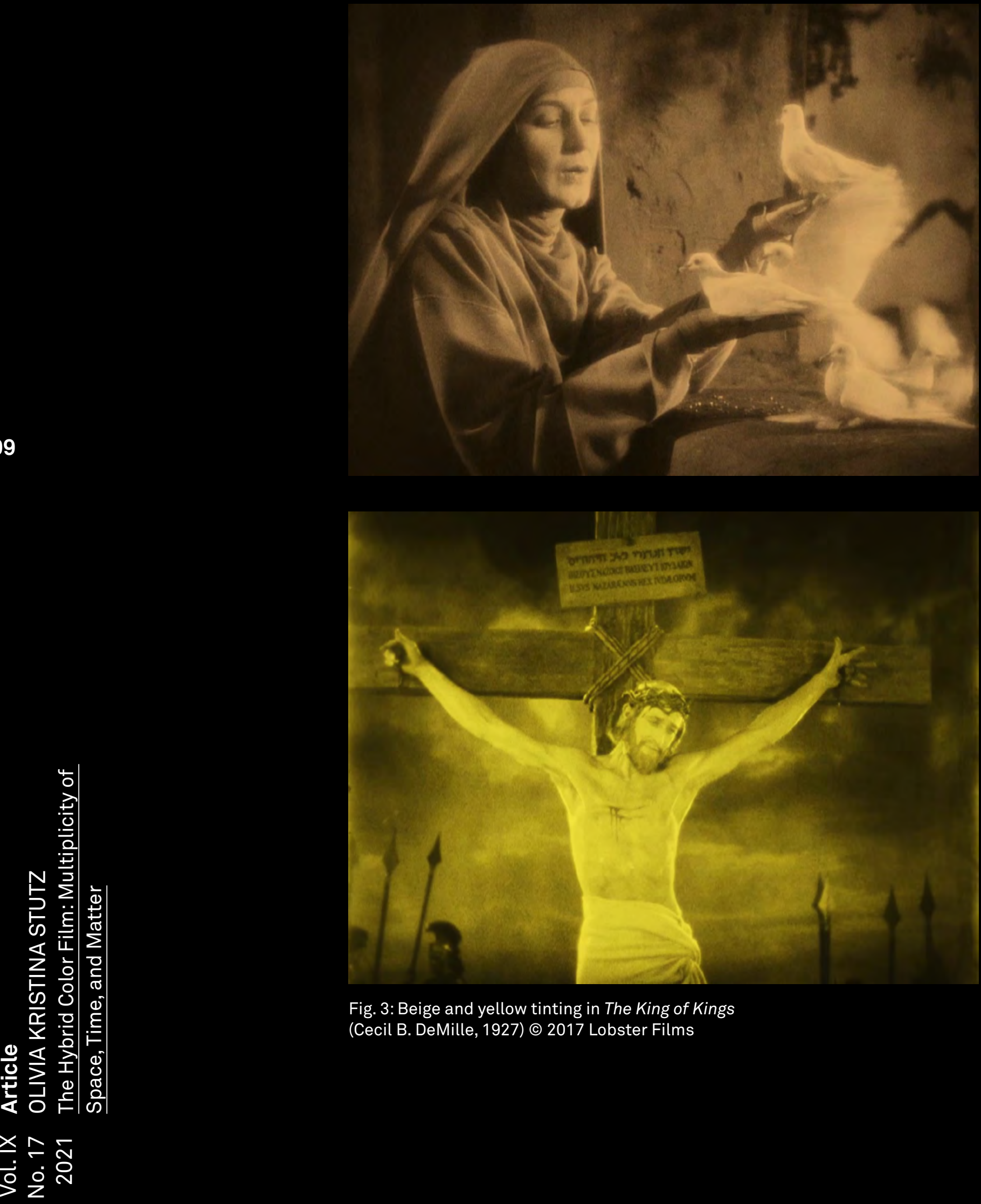

Fig. 3: Beige and yellow tinting in The King of Kings (Cecil B. DeMille, 1927) @ 2017 Lobster Films 
economic valuation of its respective color segments. Even within the realms of tinting, an internal logic becomes evident: whereas the everyday sequences are typically colored in beige, a yellow hue was chosen for the Crucifixion sequence (Fig. 3).

The film's stable color attributions - beige for the everyday, blue/white for the moonlit night, orange for the torches, yellow for Christ's agony, and two-color for the spectacle-demonstrates intratextual, structural color arrangements rather than the application of "color codes," a popular but problematic concept frequently assigned to silent cinema (Ledig and Ullmann 1988, 105-10). Color codes, in this sense, are too reductionist a concept to describe the nuanced cinematic language of The King of Kings, which creates an overarching aesthetic film "text" based on an immanent logic in its choice of color processes, its construction of (simultaneous or non-simultaneous) cinematic spaces, and the way it deals with film time (or narration). In fact, because of these complex interdependences, it may be preferable to refer to the color process in the film as a changing color space or even a cinematic chronotope. Thus, The King of Kings not only experimented with color matter but also put a new kind of visual storytelling for feature films to the test.

Aesthetically speaking, however, the particular arrangement of these color spaces - how they unfold over the course of the film - not only fundamentally influences the color scheme and overall style of the film but also generates a variety of dazzling color contrasts. These are, for instance, contrasts in the hue and extension of the different color processes, contrasts in quality in relation to two-color Technicolor, and many cold-warm and complementary contrasts in the relationships within the images, as in the Kiss of Judas

sequence. Fig. 4 demonstrates some of these characteristics visually by displaying the color luminance over the course of The King of Kings. The VIAN visualization (Flueckiger and Halter 2020) presents the film's color scheme at a glance, allowing us to instantly detect chromatic transformations and material interactions, and also draws special attention to the light-dark differences between the individual color processes.

The individual color spaces can, of course, also merge into each other as a phenomenological experience or (conversely) interrupt the film's color consistency and disturb the spectator's immersion in the filmic world. The question is: What happens in hybrid color films aesthetically, phenomenologically, and epistemologically during the transition from monochrome tinting to the mimetic two-color technology or the synchronous mixture of two different coloring techniques? Significantly, all the shifts from one color process to another-from the opening to the ending of a sequence in a particular color system-are exclusively fadeouts or fade-ins. The "smooth" cinematic technique eliminates the moment of visual shock that might otherwise occur if the transition were too abrupt. There is also a distinct pleasure in seeing the same characters first in monochrome and then in twocolor. For instance, comparing a shot of Mary of Bethany (Josephine Norman) in a beige tint with the shot of her in the Technicolor no. III Resurrection sequence is a visually spectacular experience; there is suddenly an excess of color, reminiscent of an oil-painting, that creates an unparalleled Pygmalion effect. The King of Kings, therefore, not only embodies manifold color matter and filmic spaces, but also negotiates potentially diverse modes of seeing and diverse discourses on the subject of color itself. 


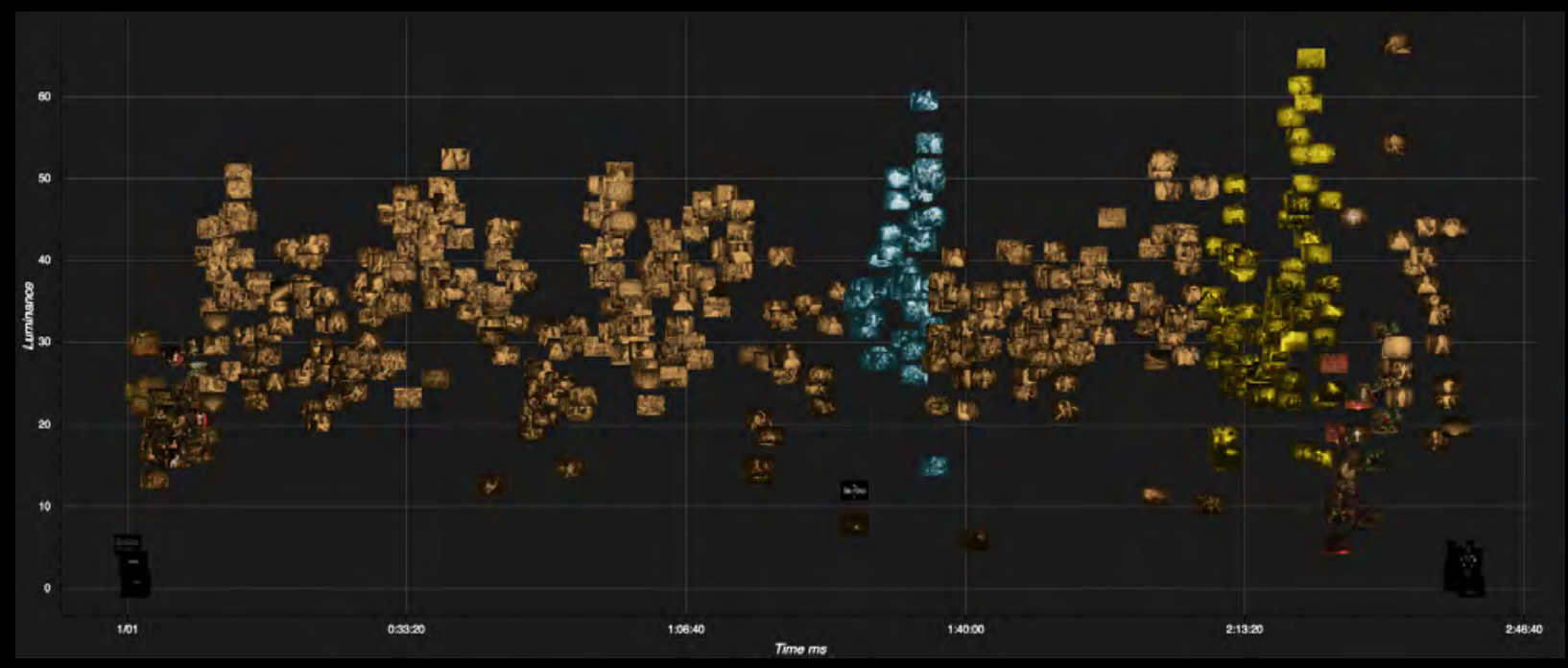

Fig. 4: VIAN color scheme visualization of luminance (y-axis) over time (x-axis) of The King of Kings (Cecil B. DeMille, 1927) @ 2017 Lobster Films

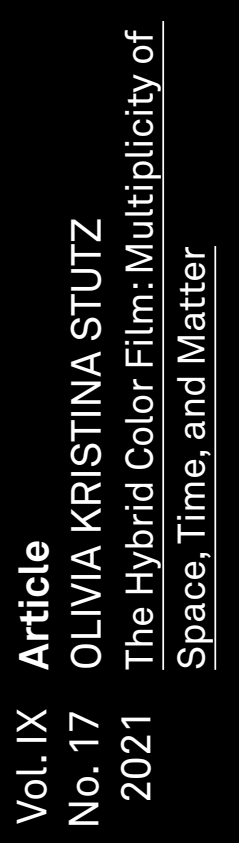




\section{Time}

Finally, the categories of matter and space must be contextualized by the category of time. The parameter of filmic time is usually associated with narration and temporal organization using cinematic techniques (montage, ellipsis, etc.); however, the focus here is on analyzing the hybrid color film's inscribed temporalities from a historiographical perspective. While the film industry first introduced blackand-white, hand-coloring, tinting, and toning practices in the late 1890s and early 1900 s, Technicolor No. III was not patented (let alone adopted) until 1926 (Ball and Comstock 1926). The unusual quality of The King of Kings lies in its combination of three "historical" coloring (as well as black-and-white) methods with a "contemporary," recently evolved color film technology, thus mixing the signatures of different film periods. The combination of these various processes from different eras can be described by the term simultaneity of the non-simultaneous, an expression of the modern paradigm of the "coexistence of realities from radically different moments of history" (Jameson 1991, 307).

However, this notion also gives the impression that film styles and techniques are historically fixed and can only be assigned to a specific era. This, of course, is not the case: for example, the tinting of the late 1920s was stylistically different from that of the early 1900s. Yet, like black-andwhite film, there is a certain continuity in terms of the characteristic "look" of a color process (whether analog or based on digital emulations) that at a particular point in time may signal "pastness" or, as in The King of Kings, a myriad of historical film epochs, creating breathtaking chromatic connections through space and time. The question is, then, from where and under what conditions does this impression of the simultaneity of the non-simultaneous arise? To avoid the danger of technological determinism, we must consider not only the patenting and initial implementation of color processes by the film industry but also their proto-cinematic practices (their diverse pasts), their existing discourse (their present), and their persistence throughout cinema history (their potential futures).

In this respect, many of the applied color processes mentioned above were derived from long-established traditions in the fields of photography or the applied arts and date back far earlier than their adoption by the film industry (Gunning 2015, 17). Moreover, tinted and toned films, alongside black-and-white films, were the visual "norm" and "good practice" for (color) films of the 1920s. This means that each process endured for over twenty years within the film industry. An even more extreme case is the craft of hand coloring, executed in The King of Kings by the film colorist Gustav Brock. Theoretically, this technique could have been replaced by stenciling in 1905 or by Handschiegl in 1916 but was not in practice. Moreover, many of the "new" mimetic color film processes of the 1920s still used "old" film coloring techniques: for instance, Handschiegl had already implemented the basic principle of dye transfer used by Technicolor no. III. In fact, Handschiegl itself was inherited from the Sanger Shepherd process (1900) used in still photography and utilized for the colorization of magic-lantern slides (Pénichon 2013, 128-29). What was perceived as "contemporary" or "new" was very often based on the prehistories of these color processes (Street and Yumibe 2013, 149).

Hence, the notion of the simultaneity of the non-simultaneous is also a question of discourse; that is, how we or the historical spectators perceive or relate to the material of the past (or present). In this sense, it 
could be a retrospective construction of "non-simultaneity" if historical processes such as hand coloring were used or, as in the case of tinting, newly adapted for the technology of sound by means of pre-tinted film stocks (Read 2009, 21-24). On the one hand, Brock $(1930,62)$ was defending his art of hand coloring as late as the 1930s, the hybrid color film's "present time"; on the other hand, contemporary critiques of The King of Kings tended to ignore the tinted or hand-colored version and typically highlighted the Technicolor sequences as signs of major technological progress. For instance, in an edition of The Film Spectator published on June 11, 1927, a film critic expressed the wish that the whole film had been shot in natural color, claiming that this would have made it "a creation of such exquisite beauty that it would have been its own apology for its lack of entertainment" (Anonymous 1927, 6 ). The critic not only dismisses the then-popular argument of an apparent "eye strain" (e.g., Henry 1926), but also grants color film technology a spectacular visual quality in its own right. Together with the general lack of any reaction to applied colors at the time, this implies either that the "new" coloring techniques were the only ones considered worth mentioning or that tinting or toning were not regarded as actual color but as mere filmic realism (Street and Yumibe 2019, 206). Thus, the impression of the temporal notion of the simultaneity of the nonsimultaneous when applied to the hybrid color film is a relational one whose significance or meaning differs according to the viewer, whether it be the historical film craftsman or film critic, or even the modern spectator, for whom all analog color processes are ancient.

In terms of the possible futures of these color processes, the mimetic technology takes on a special position in retrospect, in that, to put it provocatively, it anticipated the same (albeit, two-colored) dye-transfer printing principle as the subtractive three-color process, Technicolor no. IV, which later became the standardized color film technology of the Hollywood studio system (Bordwell 1985a). In this sense, hybrid color films of the 1920s may even represent a prologue to the potential future of the practices of a certain film production system.

This is not to say, however, that I follow a teleological approach in this article; on the contrary. Many color processes besides the later standardized Technicolor no. IV had already existed in cinema simultaneously or asynchronously across the globe for a long time. Tinting, toning, and stencil, for example, could be considered-in terms of cost, technological stability, and aesthetic quality- "standardized" color film practices of the silent era (Rakin 2021, 131-36). Toning was even used until at least the 1960s in the genre of the western (L'Abbate 2013, 143), whereas traditional hand coloring is still deployed or resurrected today in avant-garde cinema (Catanese and Parikka 2018, 53-57). Moreover, during the 1940s, the chromogenic three-color monopack Agfacolor was the main color process in Germany (Beutler 2020, 202), while in the US the subtractive two-color dye-toning process Cinecolor was one of Technicolor no. IV's main competitors until the 1950s and was regarded as a much cheaper and more practicable solution (Belton 2000, 346). As John Belton (2000, 344-45) comments: "Each [color system's] technology exists within a different set of technological, economic-industrial, and socio-cultural determinants and constraints. And, as a result, the history of each technology takes a different shape."

The expression of the simultaneity of the non-simultaneous thus becomes especially useful in bypassing 
teleological approaches to color cinema. This is particularly the case with technological determinism and the idea of the signatures of film epochs, in which color film standardization is only (and unfavorably) linked to periodization or to a linear timeline of consecutive color film styles and "maturing" technologies. Yet, as Thomas Elsaesser $(2012,597)$ puts it, there is no single history of (color) cinema; rather, there are many histories. In this sense, each color process embedded in a hybrid color film of the 1920s has the potential to shape the possible futures of color cinema, which in turn lay the basis for future hybrid color films. Thus, even though the film type (or mixed media art generally) is not necessarily synonymous with media and style transformation, it can certainly encourage the process and lead to fundamental changes. In proclaiming both a literal and metaphorical simultaneity of the non-simultaneous - combining the (diverse) pasts, (potential) present, and (possible) futures of color cinema in one film - this film type becomes rather a symptom of media change and a symbol of contemporary media archaeological approaches to film historiography (Strauven 2013, 68). The King of Kings, however, carries yet another layer of space, time, and matter: namely, its odyssey through space and time as a material artifact or as its digital reconstruction.

\section{The journey of film matter through space and time}

When we move to the last layer of space, time, and matter in The King of Kings, the concept of the transformational hybrid formulated at the outset of this case study comes into play. As such, the notion can be applied to either the film's provenance or its digital reconstruction. In terms of The King of Kings, digital reconstructions can be considered a further material-aesthetic and epistemological sedimentary layer of cinematic provenance that not only influences the appearance of the film but also changes its material basis. In this sense, the film is now marked by a distinct transformational hybridity. And since the analog source material becomes especially distorted in the digital age, due to the digitization process (Flueckiger, Daugaard, and Stutz 2020, 80), the film's "transformation" is also linked to filmethical considerations. In light of this, it is important to take another look at the Lobster 4k reconstruction of The King of Kings.

The comparison of the Mary Magdalene sequence in the Bluray version (Fig. 1) with a respective Technicolor no. Ill dye-transfer material (of the same shot, but from another archive, Fig. 5) already brings several differences to light-even if one takes into account the aesthetic diversity of individual film copies of the same color process. These are most significant in the reds, which are too magenta in the digital version in contrast to the color process's characteristic warm orange-reds, or again in the digital version's too-cold, pink flesh tones.

VIAN visualizes these material differences particularly well by means of selector-dependent colorimetry: that is, the quantification of the perception of color on a micro level (Fig. 6).

Furthermore, according to the Blu-ray bonus material, the torch flames that light up the night sky in the Kiss of Judas sequence are not Brock's original brushstrokes but digital reconstructions, as are the blue toning and the final part of the Resurrection sequence. In terms of the "digital hand coloring," the outlines of the flames were transferred from DeMille's private-unfortunately, 


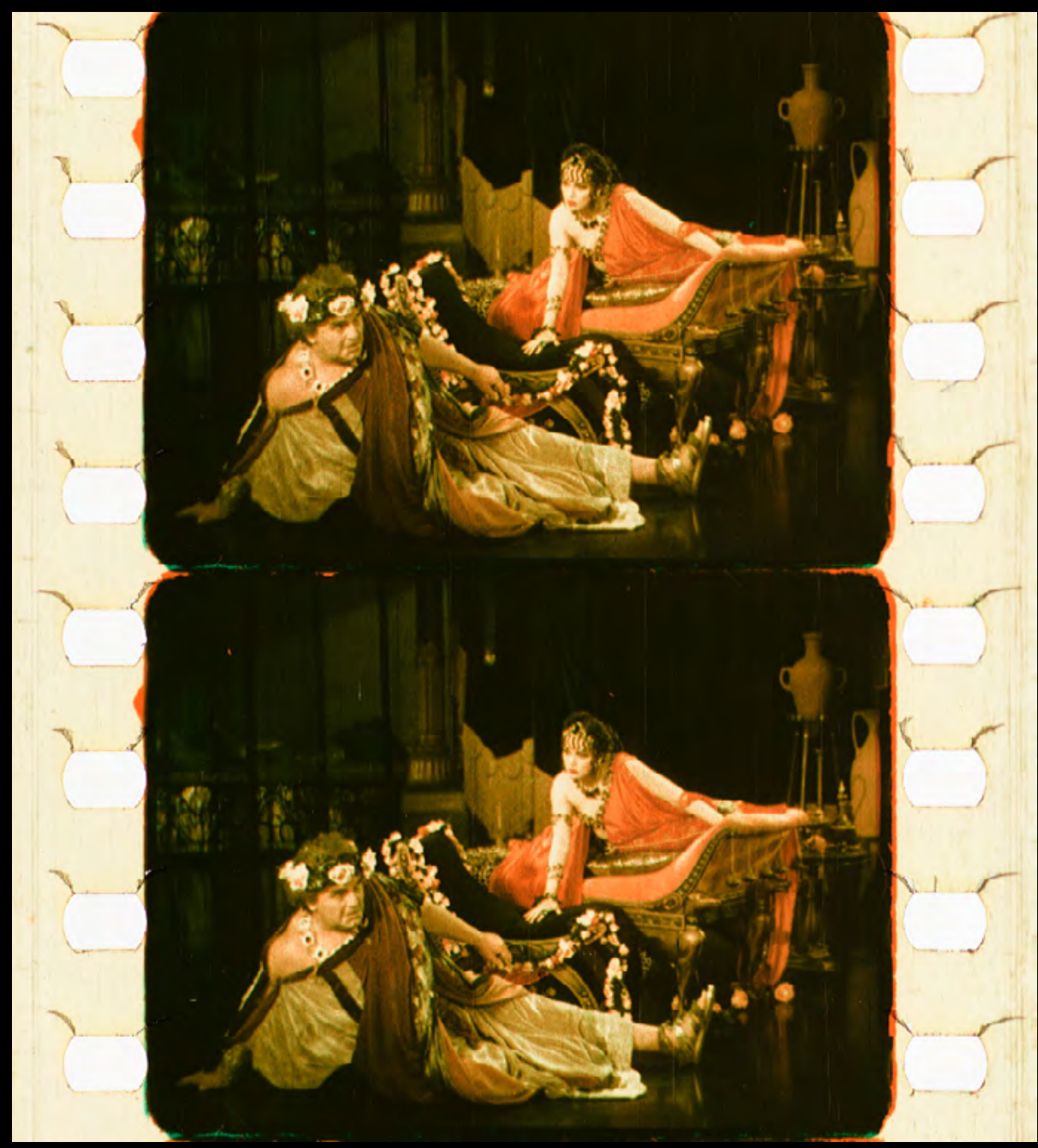

Fig. 5: Photographs of the Technicolor no. III dye-transfer nitrate print of The King of Kings (Cecil B. DeMille, 1927) at the George Eastman Museum by Olivia Kristina Stutz. Source: Timeline of Historical Film Colors: https://filmcolors.org/galleries/the-king-of-kings-1927/ [accessed November 7, 2021].

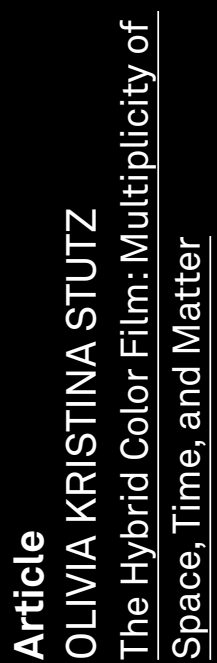

$x \sim \bar{N}$
$\dot{\sim}$ 응
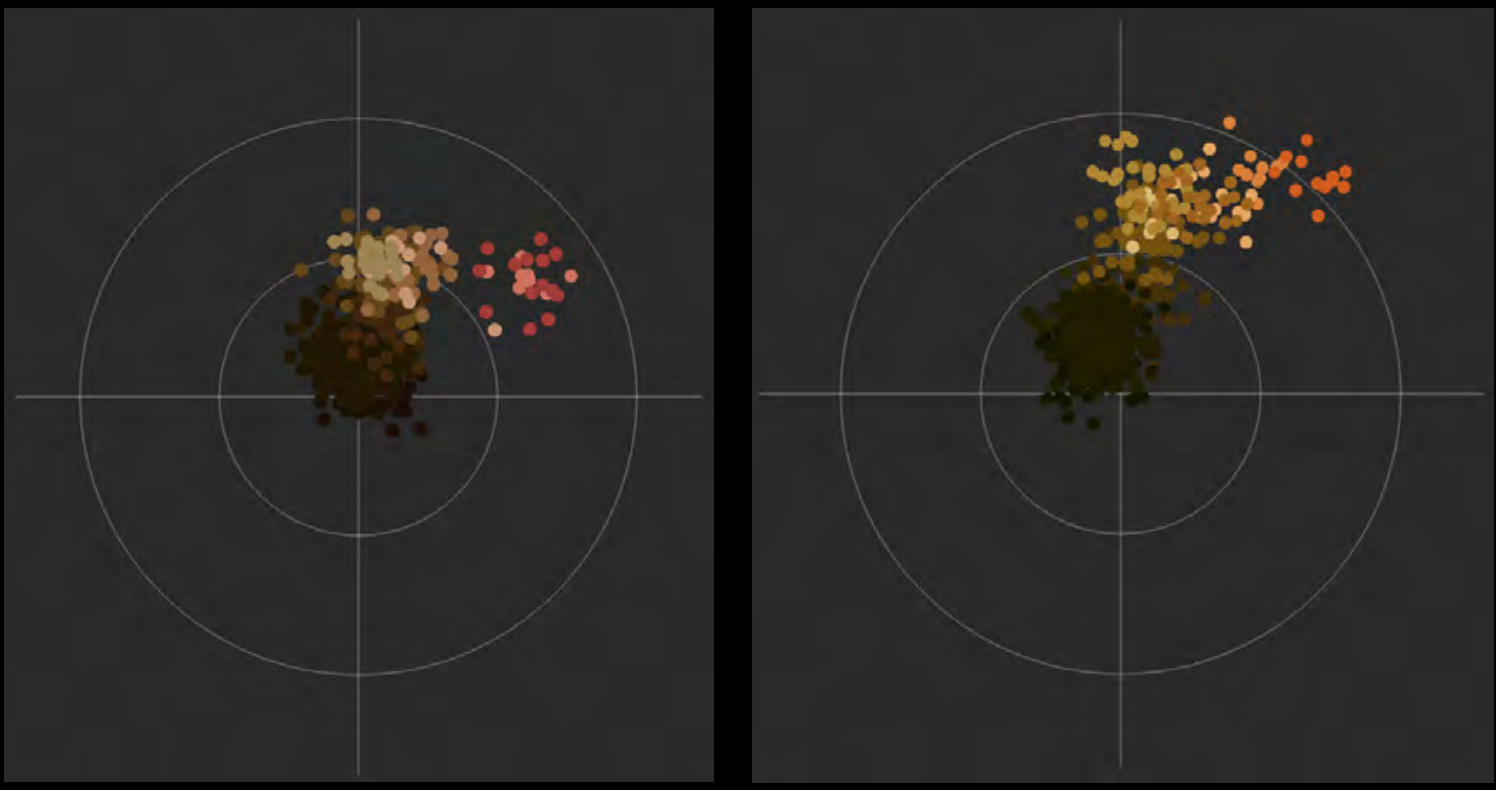

Fig. 6: VIAN colorimetry reveals a significant visual difference, especially in the red spectrum, between the digital version of The King of Kings @ 2017 Lobster Films (left) and the Technicolor no. III dye-transfer nitrate print (right) 


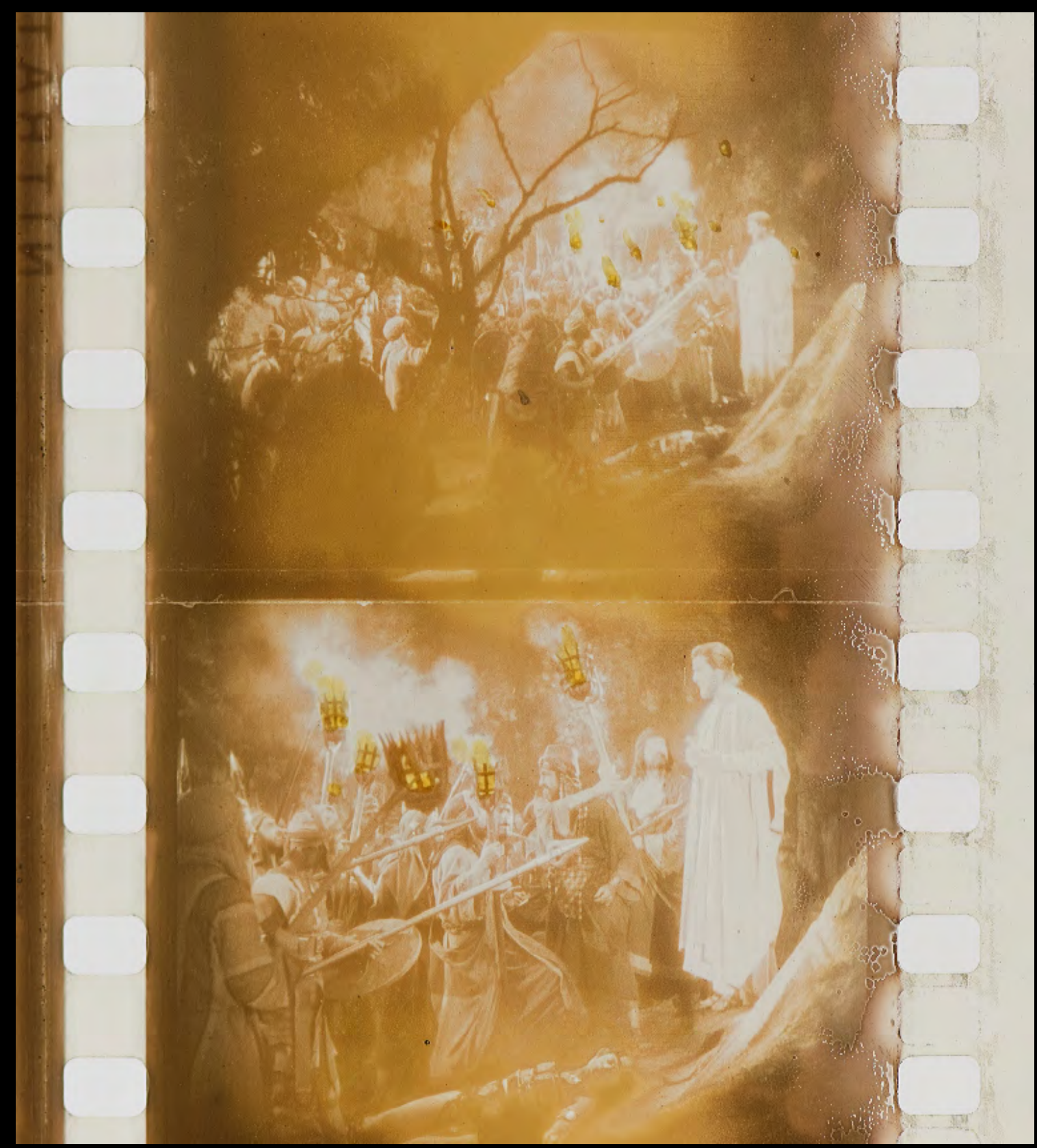

Fig. 7: Photographs of the toned and hand-colored nitrate print from the 1927 version of The King of Kings (Cecil B. DeMille, 1927) at the George Eastman Museum by Olivia Kristina Stutz. Source:Timeline of Historical Film Colors: https://filmcolors.org/galleries/the-king-ofkings-1927-4/ [accessed November 7, 2021]. 

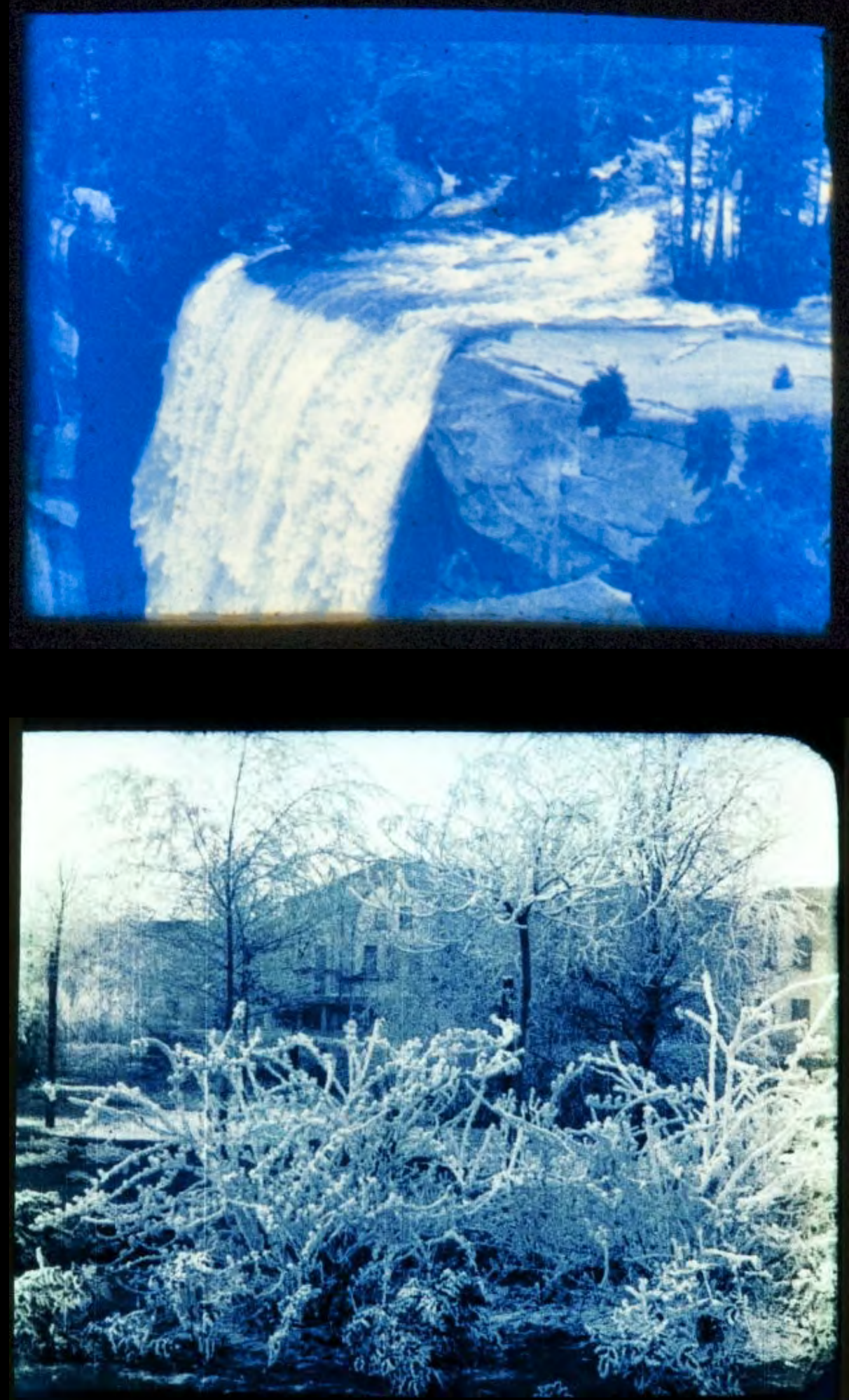

Fig. 8: Comparison of the shade of iron blue in the Eastman Kodak Company (1918) manual: Tinting and Toning of Eastman Positive Motion Picture Film. Rochester, NY. (Credit: Clayton Scoble and Stephen Jennings, Harvard University, Fine Arts Library) [top] with the shade in the Agfa Kine-Handbuch, (ca. 1925). Berlin, Actien-Gesellschaft für Anilin-Fabrikation. (Photograph by Barbara Flueckiger) [bottom]. Source: Timeline of Historical Film Colors: https://filmcolors.org/ timeline-entry/1215/ [accessed November 7, 2021]. 
already decaying - nitrate print (Fig. 7).

Although the analog hand coloring of the 1920s and the digital hand coloring of today share some basic similarities in the sense of their "autonomously" applied colors, they are still extremely different coloring practices, especially in terms of technology, epistemology, materiality, tactility, haptics, and aesthetics. This last aspect becomes particularly apparent when comparing the huewhich is more yellow and less orangewith the transparencies of the different color transitions in the tongues of flame, which are more delicate in the analog print (Fig. 2 and 7). The nitrate print, however, in which the decaying tone at first sight looks more of a sepia color, was also used as the main reference for the reconstruction of the blue toning. Owing to its severe state of decay, the rest of the image areas were based upon a black-and-white duplicate negative from the 1970s, and "digitally toned" in the blue-white color. A comparison of the two images demonstrates particularly well how specific colors of some historical film prints can deteriorate over time, especially in the case of the iron-blue tone (Read and Meyer 2000, 272), and how such digital reconstructions walk a very fine line between historical accuracy and the application of "imaginative" digital colors. Even if it is known for sure that the film material was toned blue, the specific shade still has to be ascertained: iron tone, for instance, had many different shades of blue. This fact can be demonstrated by a visual comparison of two shades of iron blue in historical color film manuals (Fig. 8).

The same basic critique applies to the digitally reconstructed colors at the very end of the Resurrection sequence. As a consequence of an incomplete American positive print, the reconstruction was based on a negative $A$-that is, a Technicolor no. III black-and-white negative from the US market. Although the rest of the American print served as a visual reference for the whole sequence, the filling in of the material loss at the end, known as the "concept of lacuna" (Cherchi Usai 2000, 57), reproduced "lost" colors that might have been used, representing a somewhat arbitrary recreation of analog colors using digital tools (Fossati 2012, 560). This digital resurrection of an idealized "Model Image" (Cherchi Usai 2001, 41) in Technicolor no. III-an image with no past or history-is, in the ethics of film restoration, a questionable practice $(2012,536-38)$, especially if no indication of the intervention is given. However, it is plausible in terms of the integrity of the work and the goal of filmic immersion (Lameris 2017, 119-20). Similar principles of both analog and digital coloration processes can also be identified, such as the successive transfer of two complementary colored dye layers onto a positive in the imbibition process in the 1927 film, in contrast to the superimposition of a red and a green -and, strangely, also a yellow-transparent filter layer on top of each other in the digital recreation. And yet, as explained above, these two techniques are fundamentally different, so one cannot simply replace the other. Hence, the digital version could be regarded as another layer of space, time, and matter that has been added to The King of Kings by human agency in the present, a process that fundamentally changes the film's materiality, aesthetics, and epistemology.

In this sense, every digital film reconstruction becomes a transformational hybrid, and thusespecially if the filling in of production stills or inter-titles in other digital reproductions is taken into accountsome sort of hybrid art form that is marked overall by a distinct 
ästhetische Eigenzeit. The digitally reconstructed hybrid color film is once again characterized by a simultaneity of the non-simultaneous due to the simultaneous use of different film technologies (if not epistemes) from the past and the present, which potentially lay the basis for the possible futures of moving images to come.

\section{Conclusion}

To conclude, the notion of the simultaneity of the nonsimultaneous has become a powerful historiographical tool. The King of Kings serves as a vivid example of the existence of multiple layers of space, time, and matter in the hybrid color films of the 1920s. It illustrates how such hybridizations of film technologies were progressively and creatively used to showcase the spectacular and dramatic potential of "old" and "new" color technologies, and to tell powerful visual stories that were, at one and the same time, an expression of the film's technological crisis and a manifestation of the techno-aesthetic state of the art in the 1920s. The digital reconstruction of the analog film thereby allows us to access this past, but it alters the film's material foundation, and thus fails to erase its own traces of the present.

\section{References}

Anonymous. 1927. "Cecil de Mille and 'The King of Kings."' The Film Spectator 3(8) [June]:3-6.

Ball, Joseph A., and Daniel F. Comstock. 1926. Registration of Complemental Images in Cinematography. United States Patent Office 1,579,806, filed February 4, 1922, and issued April 6, 1926.

Belton, John. 2000. “Cinecolor." Film History 12(4): 344-57.

Beutler, Michelle. 2020. "Standardizing Color Film. Technicolor No. IV and Agfacolor during the 1940s." In Color Mania. The Material of Color in Photography and Film, edited by Barbara Flueckiger, Eva Hielscher, and Nadine Wietlisbach, 197-209. Zurich; Winterthur: Lars Müller; Fotomuseum Winterthur. https://www. zora.uzh.ch/id/eprint/183284/1/ [accessed November 7, 2021].

Blaszczyk, Regina Lee. 2012. The Color Revolution. Cambridge, MA: MIT Press.

Bordwell, David. 1985a. "Technicolor." In The Classical Hollywood Cinema. Film Style and Mode of Production to 1960, by David Bordwell, Janet Staiger, and Kristin Thompson, 353-57. London: Routledge.

1985b. "The Introduction of Sound." In The Classical Hollywood Cinema. Film Style and Mode of Production to 1960, by David Bordwell, Janet Staiger, and Kristin Thompson, 298-308. London: Routledge.

Brock, Gustav. 1930. "Artist Explains Hand Color Role. Pioneer in Work Sees This Method as Indispensable to Treatment of Fire Sequences." Motion Picture News 41(9) [March]: 62.

Catanese, Rossella, and Jussi Parikka. 2018. "Handmade Films and ArtistRun Labs. The Chemical Sites of Film's Counterculture." NECSUS. European Journal of Media Studies 7(2): 43-63. https://doi.org/10.25969/mediarep/3459

Cherchi Usai, Paolo. 1995. "Le nitrate mécanique. L'imagination de la couleur 
comme science exacte (1830-1928)." In La couleur en cinéma, edited by Jacques Aumont, 95-109. Milan-Paris: Mazzotta/La Cinémathèque française.

2000. Silent Cinema. An Introduction. London: British Film Institute.

2001. The Death of Cinema. History, Cultural Memory and the Digital Dark Age. London: BFI.

2012. "Early Films in the Age of Content; or, 'Cinema of Attractions' Pursued by Digital Means." In A Companion to Early Cinema, edited by André Gaudreault, Nicolas Dulac, and Santiago Hidalgo, 525-49. Oxford, UK: Blackwell Publishing Ltd. https://doi.org/10.1002/9781118274453.ch27

Coates, Paul. 2010. Cinema and Colour. The Saturated Image. Houndmills, New York: British Film Institute.

Crafton, Donald. 1999. The Talkies. American Cinema's Transition to Sound 1926-1931. Berkeley, Los Angeles, London: University of California Press.

Dubois, Philippe. 1995. "Hybridations et métissages. Les mélanges du noiret-blanc et de la couleur." In La couleur en cinéma, edited by Jacques Aumont, 74-92. Milan, Paris: Edizioni Gabriele Mazzotta/Cinémathèque française.

Elsaesser, Thomas. 2012. "Is Nothing New? Turn-of-the-Century Epistemes in Film History." In A Companion to Early Cinema, edited by André Gaudreault, Nicolas Dulac, and Santiago Hidalgo, 587-609. Malden, Oxford: John Wiley \& Sons. https://doi.org/10.1002/9781118274453.ch30

Flückiger, Barbara. 2012. "Materialmix als ästhetisches und expressives Konzept." In Filmische Atmosphären, edited by Margrit Tröhler, Jörg Schweinitz, and Philipp Brunner, 73-90. Marburg: Schüren. https://www.zora.uzh.ch/id/ eprint/191807/ [accessed November 7, 2021].

Flueckiger, Barbara, Noemi Daugaard, and Olivia Kristina Stutz. 2020. "Shattered Provenance in the Digitization of Early Color Films." In Provenance and Early Cinema, edited by Joanne Bernardi, Paolo Cherchi Usai, Tami Williams, and Joshua Yumibe, 80-90. Bloomington, Indiana: Indiana University Press. https://www.zora.uzh.ch/id/eprint/203288/ [accessed November 7, 2021].

Flueckiger, Barbara, and Gaudenz Halter. 2020. "Methods and Advanced Tools for the Analysis of Film Colors in Digital Humanities." Digital Humanities Quarterly 14(4) [Special Issue Digital Humanities \& Film Studies. Analyzing the Modalities of Moving Images]. https://doi.org/10.5167/uzh-197994

Forster, Ralf. 2013. "Von der Zeichentricksinfonie zum Mischfilm. Zäsuren des bundesdeutschen Werbeanimationsfilms um 1960." Montage AV. Zeitschrift für Theorie und Geschichte audiovisueller Kommunikation 22(2): 119-31.

Fossati, Giovanna. 2009. From Grain to Pixel. The Archival Life of Film in Transition. Amsterdam: Amsterdam University Press.

. 2012. "Multiple Originals. The (Digital) Restoration and Exhibition of Early Films." In A Companion to Early Cinema, edited by André Gaudreault, Nicolas Dulac, and Santiago Hidalgo, 550-67. Malden, Oxford: John Wiley \& Sons. https://doi.org/10.1002/9781118274453.ch28

Gamper, Michael, and Helmut Hühn. 2014. Was sind ästhetische Eigenzeiten? Hannover: Wehrhahn. 
Gunning, Tom. 2015. “Applying Color. Creating Fantasy of Cinema.” In Fantasia of Color in Early Cinema, edited by Tom Gunning, Joshua Yumibe, Giovanna Fossati, and Jonathan Rosen, 17-28. Amsterdam: Amsterdam University Press.

Henry, Guy A. 1926. "The Effect of Motion Pictures on the Eyes." Transactions of the Society of Motion Picture Engineers 10(27) [October]: 116-27.

Jameson, Fredric. 1991. Postmodernism. Or, the Cultural Logic of Late Capitalism. Durham: Duke University Press.

Koselleck, Reinhart. 2000. Zeitschichten. Studien zur Historik. 5. Auflage 2018. Suhrkamp-Taschenbuch Wissenschaft 1656. Frankfurt am Main: Suhrkamp.

L'Abbate, Anthony. 2013. "L'aventure des films sonores teintés et virés aux États-Unis." 1895. Mille huit cent quatre-vingt-quinze. Revue de l'association française de recherche sur l'histoire du cinéma, no. 71 (December): 133-43. https://doi.org/10.4000/1895.4777

Lameris, Bregt G. 2017. Film Museum Practice and Film Historiography. The Case of the Nederlands Filmmuseum (1946-2000). Amsterdam University Press.

Layton, James, and David Pierce. 2015. The Dawn of Technicolor. Rochester: George Eastman House.

Ledig, Elfriede, and Gerhard Ullmann. 1988. "Rot wie Feuer, Leidenschaft, Genie, Wahnsinn. Zu einigen Aspekten der Farbe im Stummfilm." In Der Stummfilm. Konstruktion und Rekonstruktion, edited by Elfriede Ledig, Ludwig Bauer, and Michael Schaudig, 89-116. Diskurs Film 2. München: diskurs film.

Levinson, Jerrold. 1984. "Hybrid Art Forms." The Journal of Aesthetic Education 18(4) [Winter]: 5-13. https://doi.org/10.2307/3332623

Lobster Films. 2017. "Les trois versions du Roi Des Rois." In The Life of Christ from the Motion Picture The King of Kings, 17-20. Paris: Lobster Films.

Mazzanti, Nicola. 2009. "Colours, Audiences, and (Dis)Continuity in the 'Cinema of the Second Period."' Film History 21(1):67-93.

McKernan, Luke. 2013. Charles Urban. Pioneering the Non-Fiction Film in Britain and America, 1897-1925. Exeter: University of Exeter Press.

Misek, Richard. 2010. Chromatic Cinema. A History of Screen Color. Chichester: John Wiley \& Sons.

O’Brien, Charles. 2012. "Motion Picture Color and Pathé-Frères. The Aesthetic Consequences of Industrialization." In A Companion to Early Cinema, edited by André Gaudreault, Nicolas Dulac, and Santiago Hidalgo, 298-314. Malden, Oxford: John Wiley \& Sons. https://doi.org/10.1002/9781118274453.ch16

Pénichon, Sylvie. 2013. Twentieth Century Colour Photographs. The Complete Guide to Processes, Identification \& Preservation. London, Los Angeles: Thames \& Hudson.

Rakin, Jelena. 2021. Film Farbe Fläche. Ästhetik des kolorierten Bildes im Kino 1895-1930. Marburg: Schüren.

Read, Paul. 2009. “'Unnatural Colours'. An Introduction to Colouring Techniques in Silent Era Movies." Film History 21(1): 9-46. 
Read, Paul, and Mark-Paul Meyer. 2000. Restoration of Motion Picture Film. Oxford: Butterworth-Heinemann.

Ryan, Roderick T. 1977. A History of Motion Picture Color Technology. London: Focal Press.

Strauven, Wanda. 2013. "Media Archaeology. Where Film History, Media Art, and New Media (Can) Meet." In Preserving and Exhibiting Media Art. Challenges and Perspectives, edited by Julia Noordegraaf, Vinzenz Hediger, Cosetta G. Saba, and Barbara Le Maître, 59-74. Amsterdam: Amsterdam University Press. https:// doi.org/10.1515/9789048513833-005

Street, Sarah, and Joshua Yumibe. 2013. "The Temporalities of Intermediality. Colour in Cinema and the Arts of the 1920s." Early Popular Visual Culture 11(2) [May]: 140-57. https://doi.org/10.1080/17460654.2013.783149 2019. Chromatic Modernity. Color, Cinema, and Media of the 1920s. New York: Columbia University Press.

Thompson, Kristin. 1985. "Major Technological Changes of the 1920s.” In The Classical Hollywood Cinema. Film Style and Mode of Production to 1960, by David Bordwell, Janet Staiger, and Kristin Thompson, 281-93. London: Routledge.

Wagner, Monika. (2001) 2013. Das Material der Kunst. Eine andere Geschichte der Moderne. München: C.H. Beck.

Yumibe, Joshua. 2012. Moving Color. Early Film, Mass Culture, Modernism. New Brunswick et al.: Rutgers University Press. 